\title{
Measurement of Factor $H$ Variants in Plasma Using Variant-Specific Monoclonal Antibodies: Application to Assessing Risk of Age-Related Macular Degeneration
}

\author{
Svetlana Hakobyan, ${ }^{1}$ Claire L. Harris, ${ }^{1}$ Agustín Tortajada, ${ }^{2}$ Elena Goicochea de Jorge, ${ }^{2}$ \\ Alfredo García-Layana, ${ }^{3}$ Patricia Fernández-Robredo, ${ }^{3}$ Santiago Rodríguez de Córdoba, ${ }^{2}$ \\ and B. Paul Morgan ${ }^{1}$
}

Purpose. The Y402H polymorphism in the complement regulator factor $\mathrm{H}(\mathrm{fH})$ is strongly associated with age-related macular degeneration (AMD) across diverse populations. Persons homozygous for histidine at this position have up to 12-fold greater risk for AMD than those homozygous for tyrosine. Knowledge of $\mathrm{fH}-\mathrm{Y} 402 \mathrm{H}$ status is, therefore, valuable in predicting risk and focusing preventive measures in the elderly. This knowledge requires genetic analysis, which is unavailable in most laboratories and which provides no information about the levels of $\mathrm{fH}$ protein, a putative linked determinant of disease risk.

MethoDs. The authors describe novel monoclonal antibodies that distinguish the two $\mathrm{fH}$ allelic variants in plasma. ELISA with these antibodies not only reliably identifies the $\mathrm{fH}-\mathrm{Y} 402 \mathrm{H}$ status, confirmed by genotyping, but also quantifies the concentration of total $\mathrm{fH}$ and the $\mathrm{fH}-\mathrm{Y} 402$ and $\mathrm{fH}-\mathrm{H} 402$ variants.

RESUlts. In young adult control subjects, mean fH concentration was $233 \mathrm{mg} / \mathrm{L}$. In elderly control subjects, mean $\mathrm{fH}$ concentration was $269 \mathrm{mg} / \mathrm{L}$, whereas in a matching AMD cohort, mean $\mathrm{fH}$ concentration was $288 \mathrm{mg} / \mathrm{L}$. Total $\mathrm{fH}$ concentration was similar in each subgroup of young and elderly control subjects; however, in the AMD group, fH concentration was significantly higher in the heterozygous subgroup. Measurement of the two variants in this subgroup showed that both were elevated to a similar degree.

Conclusions. The novel monoclonal antibody MBI-7 was used to develop a robust assay for measurement of $\mathrm{fH}$ and the variants in plasma. The simplicity of the assay means that it may be used by any clinical laboratory to identify polymorphic

From the ${ }^{1}$ Department of Medical Biochemistry and Immunology, School of Medicine, Cardiff University, Cardiff, United Kingdom; the ${ }^{2}$ Department of Molecular and Cellular Physiopathology, Centro de Investigaciones Biologicas and Centro de Investigación Biomedica en Red de Enfermedades Raras, Madrid, Spain; and the ${ }^{3}$ Department of Ophthalmology, University Clinic of Navarra University, Pamplona, Spain.

Supported by Wellcome Trust Programme Grant 068590 (BPM), Wellcome Trust University Award 068823 (CLH), Spanish Ministerio de Educación y Cultura Grant SAF2005-00913 (SRdC), and Ministerio de Sanidad y Consumo, Tecnologias Sanitarias Grant 06/90133 (AG-L).

Submitted for publication November 27, 2007; revised December 18, 2007 and January 2, 2008; accepted March 3, 2008.

Disclosure: S. Hakobyan, None; C.L. Harris, None; A. Tortajada, None; E. Goicochea de Jorge, None; A. García-Layana, None; P. Fernández-Robredo, None; S. Rodríguez de Córdoba, None; B.P. Morgan, None

The publication costs of this article were defrayed in part by page charge payment. This article must therefore be marked "advertisement" in accordance with 18 U.S.C. $\$ 1734$ solely to indicate this fact.

Corresponding author: B. Paul Morgan, Department of Medical Biochemistry and Immunology, Henry Wellcome Building, School of Medicine, Cardiff University, Heath Park Way, Cardiff CF14 4XN, UK; morganbp@cardiff.ac.uk. status and to quantify plasma levels in persons at risk for AMD. (Invest Ophthalmol Vis Sci. 2008;49:1983-1990) DOI: 10.1167/iovs.07-1523

Cof omplement factor $\mathrm{H}(\mathrm{fH})$ is the major fluid-phase regulator of the alternative pathway of complement and plays a key role in controlling complement activation in vivo. $\mathrm{fH}$ is produced mainly in the liver and is reported to be present in plasma at a concentration of approximately $500 \mathrm{mg} / \mathrm{L} .{ }^{1}$ The molecule is made up entirely of a string of 20 folded globular domains known as short consensus repeats (SCRs). ${ }^{2}$

The relevance of $\mathrm{fH}$ to homeostasis is apparent in patients with fH deficiency; uncontrolled complement activation consumes the components, rendering the patient secondarily deficient in $\mathrm{C} 3$ and, hence, susceptible to pyogenic infections. ${ }^{3,4}$ Importantly, persons deficient in $\mathrm{fH}$ are susceptible to a specific pathologic renal condition, type II membranoproliferative glomerulonephritis (MPGN II), not seen in association with primary C3 deficiency, implying a unique and undefined role for $\mathrm{fH}$ in protecting the kidney from injury. In addition, common polymorphisms and rare mutations in $\mathrm{fH}$ have been described and shown to be associated with other diseases, including atypical hemolytic uremic syndrome (aHUS) and agerelated macular degeneration (AMD). ${ }^{5}$

AMD is the leading cause of vision loss in the elderly in Western societies, with the severe, vision-threatening complications of geographic atrophy (GA) and choroidal neovascularization (CNV) accounting for nearly $50 \%$ of all blindness in the Western world. ${ }^{6}$ Two major AMD susceptibility loci (1q31, $C F H$, and 10q26, LOC387715/HTRA1) that independently contribute to risk for AMD have been identified recently by candidate region linkage studies and whole genome association analyses. $^{7-12}$ At the $\mathrm{CFH}$ locus, the $\mathrm{Y} 402 \mathrm{H}$ polymorphism, which represents a tyrosine $(\mathrm{Y})$ to histidine $(\mathrm{H})$ change at position 402 within SCR 7 of fH, is strongly associated with the disease and has been suggested as a global marker for AMD. ${ }^{13}$ Persons homozygous for the $\mathrm{H} 402$ isoform of $\mathrm{fH}$ ( $\mathrm{fH}-\mathrm{H} 402 ; 10 \%$ of Caucasians) were at increased risk for AMD compared with those homozygous for the fH-Y 402 variant, which ranged between 3-fold and 12-fold in the published cohorts. No increased risk was found in Japanese or Chinese cohorts; however, the $\mathrm{H} 402$ variant is rare in these populations. ${ }^{14-16}$

Identification of H402-homozygous persons at high risk for disease would enable clinicians to provide an accurate risk assessment and initiate strategies to reduce extrinsic risk factors or even to implement prophylactic therapy. Current methods for identifying the fH-Y402H status of a patient require extraction of DNA followed by tedious and expensive sequencing analysis that can only be provided within specialized diagnostic laboratories. A serum assay that differentiates the relevant $\mathrm{fH}$ variants would simplify diagnosis and enable the screening of relevant at-risk populations. Additionally, it would provide information on the serum levels of $\mathrm{fH}$ that may be relevant to disease risk. Although the variants differ by only a 
single amino acid, we reasoned that monoclonal antibodies (mAbs) might be generated that would differentiate between the two, permitting the development of an assay to reveal risk for AMD from routine serum samples.

We here describe the production, characterization, and use of such reagents in the development of a variant-specific, direct sandwich enzyme-linked immunosorbent assay (ELISA) for the quantification of total $\mathrm{fH}$ and the $\mathrm{fH}-\mathrm{Y} 402$ and $\mathrm{fH}-\mathrm{H} 402$ variants in serum or plasma. The assays have been validated against the gold standard of DNA genotyping and show 100\% accuracy in identifying the $\mathrm{fH}-\mathrm{Y} 402 \mathrm{H}$ status in healthy persons and AMD patients. In addition, the assays provide valuable information regarding the concentration of $\mathrm{fH}$ variants in plasma that we anticipate will help explain the association of the fH-H402 protein with AMD.

\section{Materials AND Methods}

\section{Generation of fH-Immunoglobulin Fusion Proteins as Immunogen}

Immunoglobulin fusion proteins comprising SCR6-8 of human $\mathrm{fH}$ and the Fc portion of human IgG4 (fH-Fc) were prepared using published methods. ${ }^{17,18}$ Briefly, cDNA encoding SCR6-8 of fH with $\mathrm{H}$ at amino acid position 402 in SCR7 was amplified by RT-PCR from RNA prepared from peripheral blood mononuclear cells (PBMCs). DNA was ligated in frame with the CD33 signal sequence (SigpIg; R\&D Systems, Minneapolis, MN), as previously described, ${ }^{19}$ and then subcloned into the expression vector $\mathrm{pDR} 2 \Delta \mathrm{EF} 1 \alpha$ (gift from Ignacio Anegon, INSERM U437, Nantes, France). DNA was cloned upstream of and in-frame with that encoding the hinge and $\mathrm{Fc}$ domains of human IgG4, as previously described. ${ }^{19}$ Using this vector as template, a second expression vector was prepared that encoded SCR6-8 of fH-Y402. Two-stage join-up PCR was used to introduce a mutation in the $\mathrm{H} 402$ codon such that it was replaced with Y. DNA was cloned into pDR $2 \Delta \mathrm{EF} 1 \alpha$ in-frame with DNA encoding IgG4 Fc, as described. Sequencing confirmed that no errors had been introduced by PCR. Chinese hamster ovary $(\mathrm{CHO})$ cells were transfected with these plasmids using lipofectamine (Invitrogen, Carlsbad, CA) according to the manufacturer's instructions. Stable lines were selected with $400 \mathrm{mg} / \mathrm{L}$ hygromycin B (Invitrogen) in RPMI-1640 (Gibco, Invitrogen) medium supplemented with $10 \%$ heat-inactivated fetal bovine serum (FBS; Gibco, Invitrogen) and maintained in hygromycin B $(100 \mathrm{mg} / \mathrm{L})$ in 5\% FBS-RPMI-1640. The fH-Fc constructs were purified from the culture supernatant by protein-A affinity chromatography (HiTrap Protein A; GE Healthcare, Chalfont, St. Giles, UK), as described. ${ }^{17}$

\section{Identification of Subjects Homozygous for $\mathrm{H} 402$ and Y402 Variants}

The polymorphism of $C F H$ at the nucleotide position 1277, corresponding to amino acid position 402, was analyzed by PCR. Venous blood $(5 \mathrm{~mL})$ was collected in EDTA-containing tubes. Genomic DNA was extracted from buffy coat by proteinase $\mathrm{K} / \mathrm{phenol} / \mathrm{chloroform}$ extraction and ethanol precipitation. A fragment of $458 \mathrm{bp}$ containing exon 9 of the $C F H$ gene was amplified from genomic DNA using specific primers derived from the $5^{\prime}$ and $3^{\prime}$ intronic sequences (forward, 5'-CCT TTG TTA GTA ACT TTA GTT CGT C-3'; reverse, 5'-GGT CCA TTG GTA AAA CAA GG-3'). PCR was performed with the use of a polymerase kit (Platinum Blue PCR SuperMix; Invitrogen) in a final volume of $25 \mu \mathrm{L}$ The thermal profile consisted of an initial denaturation step at $94^{\circ} \mathrm{C}$ for 3 minutes; 35 cycles of denaturation at $94^{\circ} \mathrm{C}$ for 30 seconds, annealing at $57^{\circ} \mathrm{C}$ for 1 minute, and polymerization at $72^{\circ} \mathrm{C}$ for 30 seconds; and a terminal extension at $72^{\circ} \mathrm{C}$ for 10 minutes. Amplification was verified by electrophoresis of PCR products on $1.6 \%$ agarose gels. PCR products were purified using a PCR purification kit (QIAquick; Qiagen, Valencia, CA). Direct sequencing of PCR products was performed using an amplification primer (3130xl Genetic Analyser; ABI Prism; Applied Biosystems, Foster City, CA).

\section{Purification of Full-Length $\mathrm{fH}$ from Human Plasma}

$\mathrm{fH}$ was purified from the plasma of subjects homozygous for either the H402 or the Y402 variants by a sequential three-step FPLC method at $4^{\circ} \mathrm{C}$ on ÁKTAprime (GE Healthcare). First, filtered plasma $(100 \mathrm{~mL})$ was applied to a 5-mL column (HiTrap; GE Healthcare) to which $10 \mathrm{mg}$ mouse anti-human $\mathrm{fH}$ mAb 35H9 (generated in house) was coupled. Bound protein was eluted at low $\mathrm{pH}$, and fractions containing $\mathrm{fH}$ (identified by ELISA) were pooled, dialyzed against phosphate-buffered saline (PBS; $137 \mathrm{mM} \mathrm{NaCl}, 10 \mathrm{mM}$ phosphate, $2.7 \mathrm{mM} \mathrm{KCl}, \mathrm{pH} 7.4$ ), and applied to a heparin column (HiTrap; GE Healthcare) equilibrated with PBS. Bound proteins were eluted with $1 \mathrm{M} \mathrm{NaCl}$ in PBS. Fractions containing fH were pooled and polished by gel filtration on preparative grade matrix (Superdex-200; GE Healthcare) in a XK16/70 column (GE Healthcare). Purity was confirmed by sodium dodecyl sulfate-polyacrylamide gel electrophoresis (SDS-PAGE); using plasma from identified homozygous donors, preparations of $\mathrm{fH}-\mathrm{H} 402$ and $\mathrm{fH}-\mathrm{Y} 402$ were obtained without any detectable contaminants or aggregates by this three-step method (Figs. 1A, B). Proteins were also free of fH-like-1 (FHL-1) and fH-related proteins. Yield was $25 \%$ to $50 \%$ and was similar for the two variants. Purified $\mathrm{fH}$ was used for testing established $\mathrm{mAb}$ and as a primary standard in the ELISA.

To obtain absolute protein concentrations for the fH assay standard, aliquots of pure fH-Y402 and fH-H402 (in $20 \mathrm{mM}$ Tris buffer [pH 7.4 ] $150 \mathrm{mM} \mathrm{NaCl}$ ) of known absorbance at $280 \mathrm{~nm}$ were lyophilized to dryness and hydrolyzed by incubation in $6 \mathrm{M} \mathrm{HCl}$ for 24 hours at $110^{\circ} \mathrm{C}$. Standard (norleucine, $3 \mathrm{nM}$ ) was added, and the resultant amino acids were quantified on an amino acid analyzer (Biochrom 20; Pfizer, New York, NY). From these data, extinction coefficients $(\varepsilon)$ at $280 \mathrm{~nm}$ for the fH-Y 402 and $\mathrm{fH}-\mathrm{H} 402$ proteins were calculated to be 2.0 and $1.9 \mathrm{~cm}^{-1}(\mathrm{mg} / \mathrm{mL})^{-1}$, respectively, reflecting the additional absorbing Y residue in the former. A mean value of $1.95 \mathrm{~cm}^{-1}(\mathrm{mg} / \mathrm{mL})^{-1}$ was used for subsequent $\mathrm{fH}$ preparations so that an absorbance at $280 \mathrm{~nm}$ of 1.0 corresponded to $513 \mathrm{mg} / \mathrm{L}$.

\section{Immunization and Generation of Monoclonal and Polyclonal Antibodies}

Female BALB/c mice were immunized subcutaneously four times at 3-week intervals with $100 \mu \mathrm{g} \mathrm{fH}(6-8)-\mathrm{H} 402-\mathrm{Fc}$ in Freund adjuvant, as described. Three weeks after the last injection, the mouse with the highest titer of anti-fH antibodies (tested in ELISA) was boosted intraperitoneally with $100 \mu \mathrm{g} \mathrm{fH}(6-8)-\mathrm{H} 402-\mathrm{Fc}$ in PBS. Three days later, the spleen was harvested, and splenocytes were fused with a mouse myeloma cell line Sp2/0-Ag, as described. ${ }^{20}$ Hybridoma clones were selected and screened in ELISA for reactivity toward purified $\mathrm{fH}$ from pooled plasma. Positive clones were further screened for reactivity by comparing their binding activity to purified $\mathrm{fH}-\mathrm{H} 402$ and $\mathrm{fH}-\mathrm{Y} 402$ in ELISA. Hybridomas producing mAbs that recognized only fH-H402 variant were identified, subcloned, and expanded. The mAbs were purified by protein $G$ affinity chromatography (HiTrap Protein G; GE Healthcare). The isotype of the mAb was determined using an isotyping kit (IsoStrip Mouse Monoclonal Antibody Isotyping Kit; Roche Applied Science, Indianapolis, IN) according to the manufacturer's instructions. A similar strategy was adopted for obtaining fH-Y402specific mAb by immunizing with $\mathrm{fH}(6-8)-Y 402-\mathrm{Fc}$. No hybridomas producing $\mathrm{mAb}$ specific for the $\mathrm{fH}-\mathrm{Y} 402$ variant were identified in any of three fusions.

Rabbit antiserum against $\mathrm{fH}$ was produced by repeated immunization with pure $\mathrm{fH}$ in adjuvant. Specific immunoglobulin was purified from antiserum by affinity chromatography using $\mathrm{fH}$ immobilized on a NHS column (Hi-Trap; GE Healthcare). Aliquots of mAb and affinitypurified rabbit polyclonal anti-fH antibody were labeled with horseradish peroxidase (EZ-Link Plus Activated Peroxidase Kit; Pierce Biotechnology, Inc., Rockford, IL). Animals were handled in accordance with 
FiguRe 1. (A) Gel-filtration chromatogram from the final step of plasma fH purification after immunoaffinity and heparin affinity steps. The $y$-axis (milliabsorbance units [mAU]) plots absorbance at $280 \mathrm{~nm}$, and the $x$-axis plots retention time in minutes. (B) Coomassie staining of final $\mathrm{fH}$ preparations.

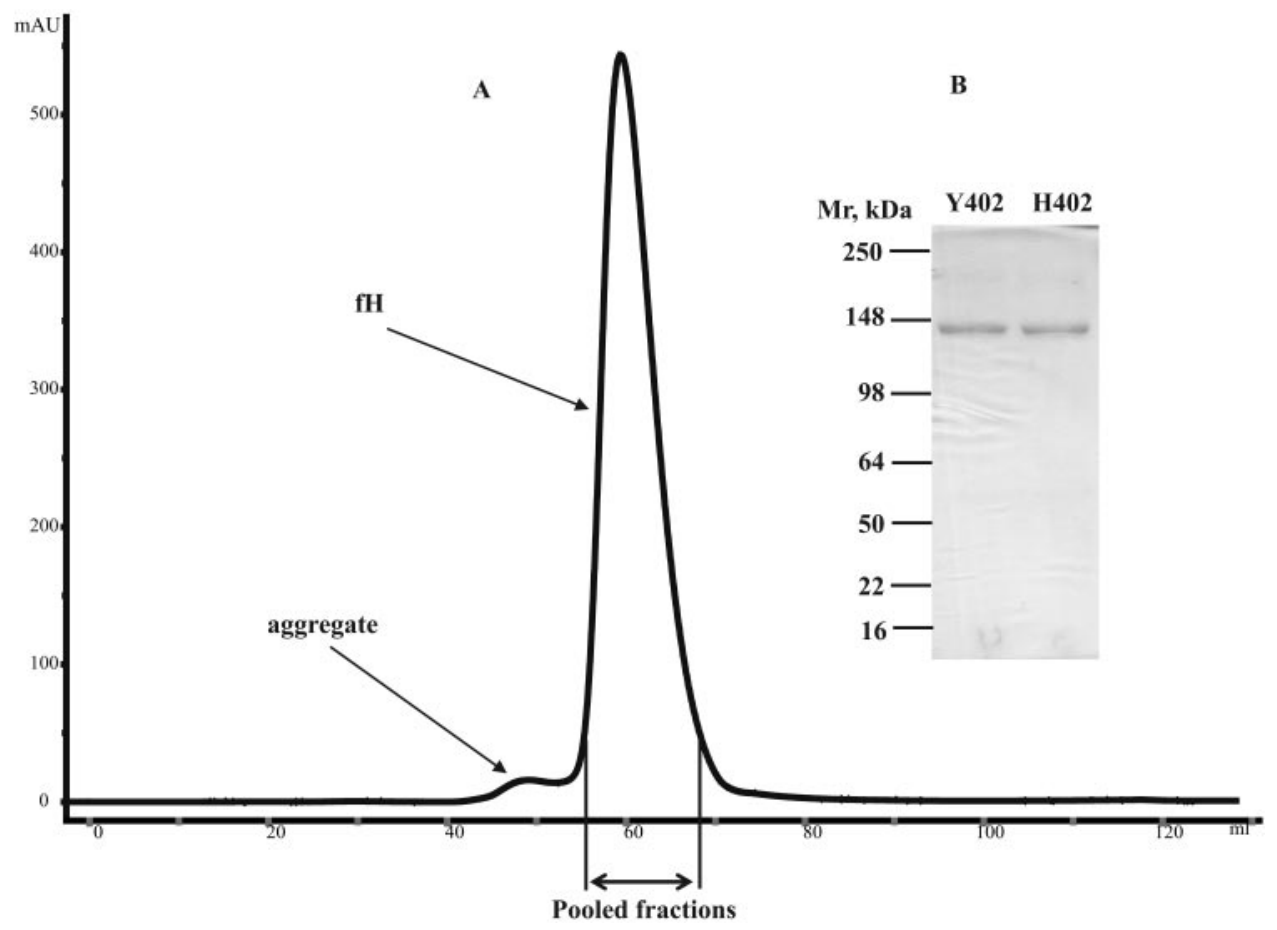

the ARVO Statement for the Use of Animals in Ophthalmic and Vision Research.

\section{Confirmation of Specificity of mAbs}

Western Blotting. fH-H402 and fH-Y402 were subjected to SDS-PAGE and transferred to a nitrocellulose membrane. After blocking with 5\% skimmed milk in PBS, the membrane was washed in PBSTween $20(0.1 \% \mathrm{vol} / \mathrm{vol})$ and incubated with the $\mathrm{mAb}(5 \mathrm{mg} / \mathrm{L})$ in PBS-5\% milk for 1 hour at room temperature. After extensive washing in PBS-Tween 20, bound mAb was detected using an HRP-conjugated goat anti-mouse $\operatorname{IgG}$ and visualized by enhanced chemiluminescence (ECL; GE Healthcare).

Dot Blotting. Serial dilutions of $\mathrm{fH}-\mathrm{H} 402$ and $-\mathrm{Y} 402$ variants were spotted on a nitrocellulose membrane using a microfiltration apparatus (Bio-Dot SF; Bio-Rad, Hercules, CA). After blocking, immobilization of the proteins was confirmed by immunodetection, as described.

ELISA. fH-H402 and - $\mathrm{Y} 402$ variants $(5 \mathrm{mg} / \mathrm{L}$ in bicarbonate coating buffer, $\mathrm{pH}$ 9.6) were immobilized on a microtiter plate for 1 hour at $37^{\circ} \mathrm{C}$. After blocking in $1 \%$ PBS-BSA, serial dilutions of mAb in blocking buffer were added. The interaction was detected by an HRP-conjugated goat anti-mouse $\operatorname{IgG}$ in combination with orthophenylenediamine (OPD; AbD Serotec, Martinsreid, Germany).

Surface Plasmon Resonance Analysis. Binding of mAb to fH-H402 and -Y402 variants was analyzed by surface plasmon resonance using a biosensor (Biacore 3000; Biacore, Uppsala, Sweden). fH-H402 or -Y 402 (300 RU) was immobilized on the CM-5 sensor chip using the amine-coupling kit (Biacore) according to the manufacturer's instructions. The reference flow cell was activated with ethyl- $N$-(3diethylaminopropyl)carbodiimide and $\mathrm{N}$-hydroxysuccinimide and was blocked with ethanolamine. Binding experiments were performed in HBS-P buffer (10 mM HEPES, pH 7.4, $150 \mathrm{mM} \mathrm{NaCl,} \mathrm{0.005 \%} \mathrm{P20}$ surfactant). $\mathrm{mAb}$ was injected in triplicate at concentrations of 0 (blank control), $6.25,12.5,25,50$, and $100 \mathrm{nM}$, at a flow rate of $20 \mu \mathrm{L} / \mathrm{min}$ for 1 minute and a dissociation time of 15 minutes. Reference curves were obtained by injection of mAb over the reference flow cell. Experimental data were corrected for the reference and blank control and were analyzed using Biacore software (BIAevaluation 4.1). The kinetic association, $k_{\mathrm{a}}$, and dissociation, $k_{\mathrm{d}}$, constants were estimated by global fitting analysis of the binding curves to the 1:1 Langmuir interaction model. The equilibrium dissociation constant $\left(\mathrm{K}_{\mathrm{D}}\right)$ was calculated as $\mathrm{K}_{\mathrm{D}}=k_{\mathrm{d}} / \boldsymbol{k}_{\mathrm{a}}$

As a positive control in this series of experiments, mouse antihuman $\mathrm{fH}$ mAbs OX-24 21 and $35 \mathrm{H} 9$, which detect both variants of $\mathrm{fH}$, were used.

\section{Development of a Quantitative ELISA Distinguishing the fH-Y402H Variants}

Affinity-purified rabbit anti-fH was diluted in coating buffer and dispensed into a 96-well microtiter plate at $0.5 \mu \mathrm{g} /$ well. After 1 hour at $37^{\circ} \mathrm{C}$, the plate was washed in PBS/0.1\% Tween 20 (PBS/T) and then blocked with $1 \%$ BSA in PBS. After washing, standards or serum samples $(100 \mu \mathrm{L}$, diluted 1:5000 in PBS) were added in triplicate or duplicate and incubated for 1 hour. Wells were washed and either HRP-labeled affinity-purified rabbit anti-fH $(100 \mu \mathrm{L} ; 1 \mathrm{mg} / \mathrm{L})$ or HRPlabeled H402-specific mAb $(100 \mu \mathrm{L} ; 1 \mathrm{mg} / \mathrm{L})$ added to measure total $\mathrm{fH}$ or fH-H402, respectively. After 1 hour, wells were washed three times, and bound antibody was detected using OPD substrate. Development was stopped by the addition of $10 \%$ sulfuric acid, and absorbance at $492 \mathrm{~nm}$ was measured. All incubation steps were performed for 1 hour at $37^{\circ} \mathrm{C}$ unless stated otherwise. Purified $\mathrm{fH}-\mathrm{H} 402$ and an equimolar mixture of both variants were used as standards for estimation of plasma $\mathrm{fH}-\mathrm{H} 402$ and total $\mathrm{fH}$, respectively. Concentrations of total $\mathrm{fH}$ and $\mathrm{fH}-\mathrm{H} 402$ in plasma were calculated by reference to the appropriate calibration curve prepared from the standards and expressed as milligram per liter of plasma. Standards were included on each plate, and the genotypes of subjects were not known before assay. Concentration of fH-Y402 was calculated by subtraction of fH-H402 from total fH concentration. The detection limit and working range in the ELISA were determined, as described. ${ }^{22}$

\section{Measurement of $\mathbf{f H}$ Variants in Plasma Samples from Healthy Donors and AMD Patients}

Samples were collected for studies approved by the Ethics Committee of the University of Navarra, and the study described adhered to the tenets of the Declaration of Helsinki. Written informed consent was obtained from all participants.

EDTA plasma was obtained from freshly drawn blood from 63 healthy young volunteers (Cardiff cohort; mean age, 35.0 years). 
Plasma was separated within 1 hour of collection and was stored in aliquots at $-80^{\circ} \mathrm{C}$. $\mathrm{fH}$ variant concentrations in plasma samples were measured as described. Identical standards were used in each ELISA plate, and samples from control subjects and AMD patients were randomly assigned to plates to eliminate any possibility of bias in the assay.

$\mathrm{fH}$ concentration and the concentrations of the $\mathrm{Y} 402$ and $\mathrm{H} 402$ variants were also measured in plasma samples from 53 AMD patients (36 with the wet form and 17 with the dry form) and 75 age- and sex-matched control subjects (Spanish cohort). Most participants in the Spanish cohorts were current or recent smokers, making it impossible to independently assess effects of smoking behavior. All controls were examined by trained ophthalmologists to screen for any form of AMD.

\section{Statistical Analysis}

Data evaluation was performed with SPSS 13.0 (SPSS Inc., Chicago, IL). Obtained data were checked for normality with Komologrov-Smirnov test. The fH concentration in human plasma was expressed as the mean \pm SD for each group. After a significant one-way ANOVA, differences between groups were evaluated using Student's $t$-test for independent samples. $P<0.05$ was considered significant.

\section{RESUlts}

\section{Preparation and Characterization of Anti-fH-H402 mAb}

From 20 positive wells cloned by limiting dilution, three stable anti-fH hybridomas were obtained that preferentially bound $\mathrm{fH}-\mathrm{H} 402$ in screening ELISA; all were $\operatorname{IgG}_{1}$ isotype. One of these, designated MBI-7, was confirmed in subsequent ELISA (Fig. 2A), dot blot, and Western blot (Fig. 2B) assays to react exclusively with fH-H402. Blotting of plasma samples from heterozygous donors or those homozygous for fH-H402 or fH-Y402 confirmed the specificity of MBI-7 for $\mathrm{fH}-\mathrm{H} 402$ (Fig. 2C). The mAb was grown in bulk and purified. As a further test of specificity, plasma from homozygous or heterozygous do- nors was applied to a column of MBI-7-sepharose. This column failed to bind any fH from fH-Y402 homozygous donors, efficiently bound fH-H402 from fH-H402 homozygous donors, and selectively bound only fH-H402 from heterozygous donors (data not shown).

Comparison of the relative affinities of MBI-7 and OX-24 for fH-Y402 and fH-H402 was performed by surface plasmon resonance analysis (Biacore 3000; Biacore). The 1:1 Langmuir interaction data-fitting model was used to predict dissociation constants $\left(\mathrm{K}_{\mathrm{D}}\right.$; Table 1). MBI-7 failed to bind $\mathrm{fH}-\mathrm{Y} 402$ but bound fH-H402 with a $\mathrm{K}_{\mathrm{D}}$ of $1.7 \mathrm{nM}$, whereas OX-24 bound both variants with a similar $\mathrm{K}_{\mathrm{D}}$ (approximately $0.1 \mathrm{nM}$ ).

\section{Establishment of a Sandwich ELISA for Quantification of Total fH and Its $\mathbf{H} 402$ Variant}

Sandwich ELISA for quantification of the two forms of $\mathrm{fH}$ in plasma or serum samples was developed by using affinitypurified rabbit anti-fH as capture and either HRP-labeled affinity-purified rabbit anti-fH (to measure total $\mathrm{fH}$ ) or HRP-labeled MBI-7 (to measure $\mathrm{fH}-\mathrm{H} 402$ ) as detection. Calibration curves using different proportions of the $\mathrm{fH}$ variants as standard were identical for the total $\mathrm{fH}$ assay and precisely reflected the proportion of $\mathrm{fH}-\mathrm{H} 402$ for the $\mathrm{fH}-\mathrm{H} 402$-specific assay (not shown). Plasma and serum samples were diluted 1:5000 for assay; the calculated detection limit of the assay was 0.007 $\mathrm{mg} / \mathrm{L}$, and the working range was 0.01 to $0.2 \mathrm{mg} / \mathrm{L}$. Assay performance was assessed by taking multiple measures from independently diluted aliquots of the same plasma samples, either within the same assay or in separate assays. The withinassay precision ranged from $4.1 \%$ to $7.0 \%$, with an average of $5.5 \%$ for total $\mathrm{fH}$ measurement, and from $7.7 \%$ to $12.8 \%$, with an average of $11.0 \%$ for fH-H402 measurement. Between-assay precision ranged from $4.9 \%$ to $10.1 \%$, with an average of $8.0 \%$ for total $\mathrm{fH}$ measurement, and from $10.1 \%$ to $15.8 \%$, with an average of $12.5 \%$ for fH-H402 measurement.
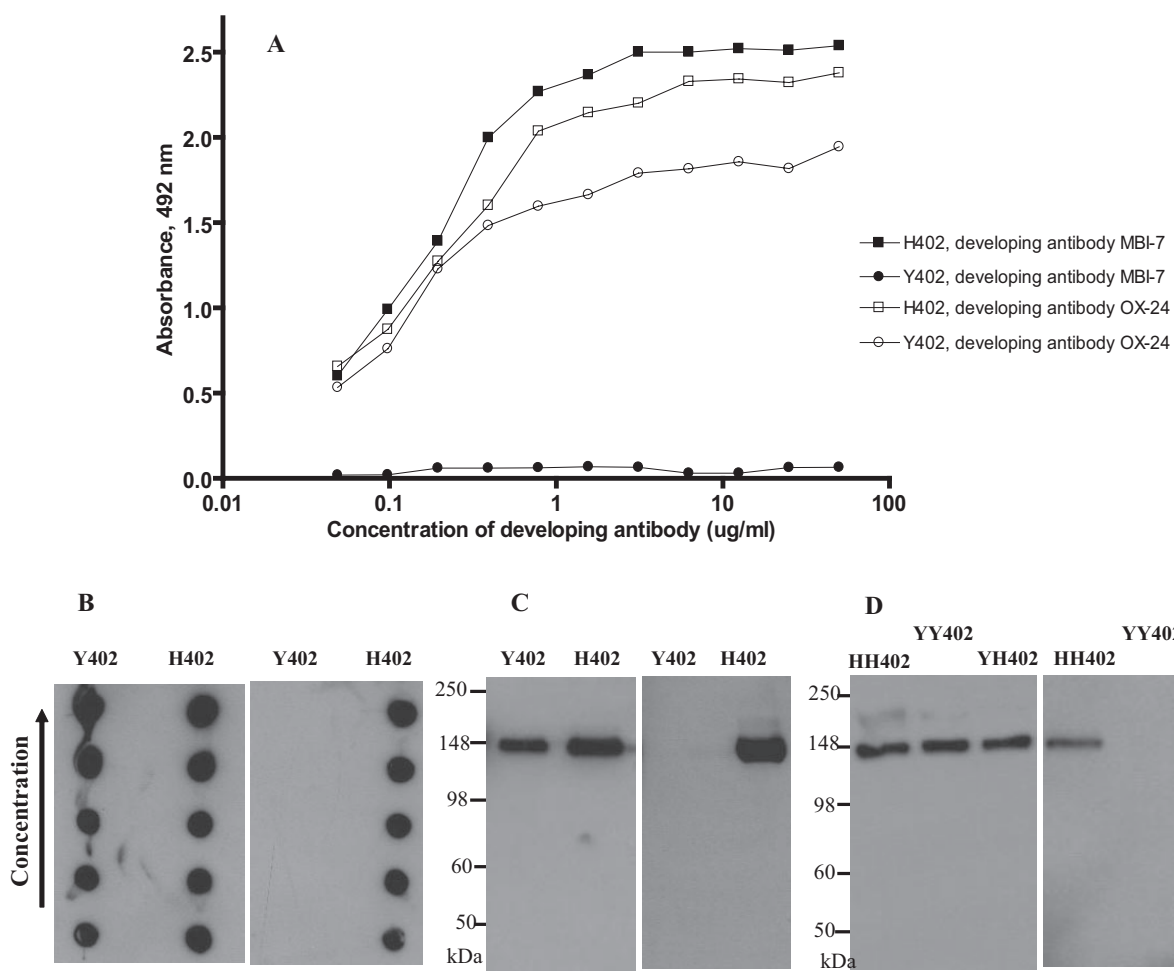

Figure 2. Specific detection of fHH402 with MBI-7. (A) ELISA with each $\mathrm{fH}$ variant directly immobilized on plate. (B) Dot blot for detection of $\mathrm{fH}$ variants using nonselective (OX24; left) and H402-specific (MBI-7; right) mAb. (C) Western blot detection of purified $\mathrm{fH}$ variants using mAb, as described. (D) Western blot detection of $\mathrm{fH}$ in plasma samples of H402 homozygous, Y402 homozygous, and YH402 heterozygous participants using $\mathrm{mAb}$, as described. 
TABLE 1. Kinetic Constants for the Interaction of OX-24 and MBI-7 Monoclonal Anti-fH Antibodies with Immobilized fH-H402 (300 RU) or fH-Y402 (300 RU) as Determined by Surface Plasmon Resonance

\begin{tabular}{lcccc}
\hline & $\begin{array}{c}\boldsymbol{k}_{\mathbf{a}} \\
(\mathbf{1} / \mathbf{M s})\end{array}$ & $\begin{array}{c}\boldsymbol{k}_{\mathbf{d}} \\
(\mathbf{1} / \mathbf{s})\end{array}$ & $\begin{array}{c}\mathbf{K}_{\mathbf{D}} \\
(\mathbf{M})\end{array}$ & $\begin{array}{c}\boldsymbol{R}_{\max } \\
(\mathbf{R U})\end{array}$ \\
\hline OX-24 with fH-H402 & $3.36 \times 10^{5}$ & $3.98 \times 10^{-5}$ & $1.19 \times 10^{-10}$ & 49.8 \\
MBI-7 with fH-H402 & $4.01 \times 10^{5}$ & $6.8 \times 10^{-4}$ & $1.69 \times 10^{-9}$ & 49.3 \\
OX-24 with fH-Y402 & $2.74 \times 10^{5}$ & $3.27 \times 10^{-5}$ & $1.19 \times 10^{-10}$ & 60.0 \\
MBI-7 with fH-Y402 & $\mathrm{NB}$ & $\mathrm{NB}$ & $\mathrm{NB}$ & $\mathrm{NB}$ \\
\hline
\end{tabular}

NB, no binding detected.

\section{Measurement of Total $\mathrm{fH}$ and Its H402Y Variants in Healthy Donors and AMD Patients}

Concentrations of total $\mathrm{fH}$ and $\mathrm{fH}-\mathrm{H} 402$ were measured by ELISA in plasma from 63 healthy donors collected in the Cardiff laboratory (Table 2; Fig. 3A); concentration of fH-Y402 was calculated by subtraction. $\mathrm{Y} 402 \mathrm{H}$ status of donors in this group, assigned by ELISA, was verified by subsequent genotyping of DNA of 30 of the donors; in every donor genotyped, the status assigned by ELISA was confirmed (data not shown). Of note, the concentrations of $\mathrm{fH}$ measured in the assay using, for the first time, absolute protein standards obtained with the extinction coefficient measured as described were less than half those quoted in the literature. ${ }^{1,23}$ Previous studies have assumed an extinction coefficient close to $1.0 \mathrm{~cm}^{-1}(\mathrm{mg} / \mathrm{mL})^{-1}$ and so have systematically overestimated plasma concentrations. In young healthy donors, the mean total $\mathrm{fH}$ concentration was $233 \mathrm{mg} / \mathrm{L}$ and was not different in the three groups (YY402, YH402, and HH402). In the HH402 group, the fHH402-specific ELISA yielded values almost identical with those obtained from the same samples in the total $\mathrm{fH}$ assay (mean, $260 \mathrm{mg} / \mathrm{L}$ vs. $249 \mathrm{mg} / \mathrm{L}$ ). YY402 values were not above background in this assay, but YH402 donors had intermediate values, as expected (Fig. 3B).

Plasma samples from a cohort of Spanish patients with diagnoses of AMD ( $n=53 ; 17$ dry AMD, 36 wet AMD) and ageand sex-matched healthy controls $(n=75)$ were also analyzed (Table 3; Fig. 4). Y402H variant status was readily assigned from the ELISA and revealed an increased frequency of the $\mathrm{H}$ allele in the patients $(\mathrm{Y} / \mathrm{H}$ ratios: $0.73: 0.27$ in controls and 0.59:0.41 in patients). Results were verified by genotyping of DNA of all donors; in every donor, the status assigned by ELISA was confirmed. Total $\mathrm{fH}$ concentration in the controls was not different among the three groups (YY402, HH402, YH402), whereas in AMD patients, total fH concentration was signifi- cantly higher in the YH402 group than in either the YY402 or the HH402 group (Fig. 4A). To further explore this observation, the concentrations of $\mathrm{fH}-\mathrm{H} 402$ and $\mathrm{fH}-\mathrm{Y} 402$ in heterozygous patients and controls was measured (Fig. 4B). Both variants were elevated to a similar degree in patients compared with controls.

\section{Discussion}

A considerable body of evidence is accumulating to support the conjecture that AMD is a disease caused by dysregulation of the alternative complement pathway. The first clues came from the demonstration that complement components and regulators are abundant in drusen, the pathologic hallmark of AMD.$^{24-26}$ The discovery that a common polymorphism in $\mathrm{fH}$, the principal fluid-phase regulator of the alternative pathway, is a major risk factor for AMD brought complement to the fore. ${ }^{7-10}$ Recently, several other complement associations have been described, including a common fH haplotype that includes deletion of the fH-related proteins 1 and 3 (fHR- 1 and fHR-3) and is protective against AMD. ${ }^{27,28}$ The common F/S polymorphic variant in $\mathrm{C} 3$, the key player in the alternative pathway, has recently been reported to modulate risk for $\mathrm{AMD},{ }^{29}$ and protective haplotypes in the linked $\mathrm{C} 2 / \mathrm{fB}$ genes have been described. ${ }^{30,31} \mathrm{~A}$ recent analysis of polymorphisms in the gene encoding $\mathrm{fH}$ described seven SNPs that modulated susceptibility to AMD; of these, only two (rs1061170, Y402H; rs800292, I62V) caused amino acid changes in the fH protein. ${ }^{32}$ The other five were synonymous exonic substitutions or changes in noncoding regions, all of which are likely to mediate their effects by modulating expression levels of the gene to alter $\mathrm{fH}$ concentrations in plasma.

Identification of carriers of risk alleles for $\mathrm{fH}$ and other complement proteins would aid prediction of disease risk and

TABLE 2. Characteristics of fH Concentrations in the Cardiff Control Cohort

\begin{tabular}{lc}
\multicolumn{1}{c}{ Characteristics } & Values \\
\hline No. of subjects & 63 \\
Females (\%) & 62 \\
Age (years)* & $35.03 \pm 8.88(21-56)$ \\
fH concentration $(\mathrm{mg} / \mathrm{L})^{*}$ & $233.24 \pm 56.65(135.54-349.27)$ \\
Y402 homozygous (\%) & 44.4 \\
Y402 homozygous (fH; mg/L)* & $220.63 \pm 61.83(102.28-359.35)$ \\
H402 homozygous (\%) & 15.9 \\
H402 homozygous (fH; mg/L)* & $248.89 \pm 58.51(172.06-348.65)$ \\
Y402H heterozygous (\%) & 39.7 \\
Y402H heterozygous (fH; mg/L)* & $230.21 \pm 49.60(132.28-339.81)$ \\
Y402H heterozygous (H402; mg/L)* & $136.86 \pm 41.64(48.45-222.68)$ \\
Y402H heterozygous (Y402; mg/L)* & $92.95 \pm 37.84(30.54-177.67)$ \\
Y402: H402 allele frequency & $0.64: 0.36$ \\
\hline
\end{tabular}

$\mathrm{fH}-\mathrm{Y} 402 \mathrm{H}$ polymorphic status was assigned from the ELISA and confirmed by sequencing. The total $\mathrm{fH}$ concentration and concentrations (in $\mathrm{mg} / \mathrm{L}$ ) of each variant were determined in each subgroup.

*Values are mean \pm SD (range). 

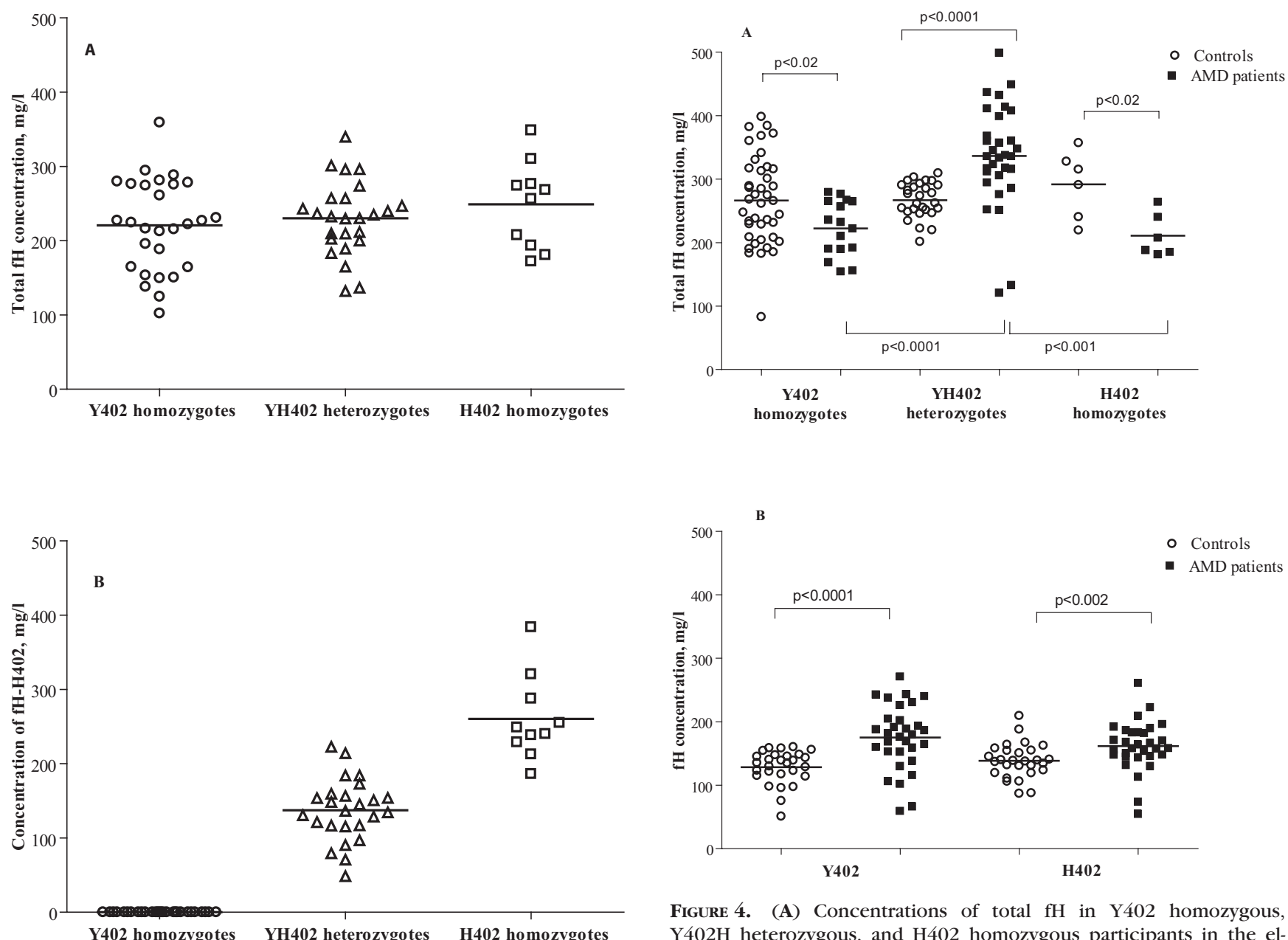

FiguRe 4. (A) Concentrations of total $\mathrm{fH}$ in $\mathrm{Y} 402$ homozygous, $\mathrm{Y} 402 \mathrm{H}$ heterozygous, and $\mathrm{H} 402$ homozygous participants in the elderly control and AMD groups. (B) Concentrations of the fH variants in $\mathrm{Y} 402 \mathrm{H}$ heterozygous participants in the elderly control and AMD

Figure 3. (A) Concentration of total $\mathrm{fH}$ in $\mathrm{Y} 402$ homozygous, $\mathrm{Y} 402 \mathrm{H}$ heterozygous, and $\mathrm{H} 402$ homozygous subjects in the Cardiff control cohort. (B) Concentrations of fH-H402 variant in Y402 homozygous, $\mathrm{Y} 402 \mathrm{H}$ heterozygous, and $\mathrm{H} 402$ homozygous subjects in Cardiff control cohort.

guide attempts to reduce risk. For example, smoking is an important extrinsic risk factor for $\mathrm{AMD}$, and it has recently been demonstrated that smoking is a much greater risk factor groups.

in those carrying the $\mathrm{H} 402$ allele. ${ }^{33,34}$ Targeting smoking cessation therapies to this group would be of particular benefit. Interestingly, smoking has previously been associated with lower plasma levels of $\mathrm{fH}^{35}$ Current genotyping methods are not well suited for rapid screening in the clinic; a rapid, simple, and accurate serum test, amenable to near-patient use, is there-

TABLE 3. Characteristics of fH Concentrations in the Spanish Control and AMD Cohorts and Concentrations (in mg/L) of Each Variant Were Determined in Each Subgroup

\begin{tabular}{lcc}
\hline & Controls & AMD \\
\hline No. of subjects & 75 & 53 \\
Females (\%) & 40.0 & 43.4 \\
Age (years) & $72.92 \pm 6.40(58-89)$ & $75.98 \pm 8.13(56-93)$ \\
FH concentration (mg/L)* & $569 \pm 55.62(83.05-398.38)$ & $287.84 \pm 88.44(120.49-498.76)$ \\
Y402 homozygous (\%) & 54.7 & 30.2 \\
Y402 homozygous (fH; mg/L)* & $266.48 \pm 69.03(83.05-398.38)$ & $222.37 \pm 43.49(150.41-279.41)$ \\
H402 homozygous (\%) & 8.0 & 11.3 \\
H402 homozygous (fH; mg/L) & $291.87 \pm 52.89(219.47-357.16)$ & $210.91 \pm 34.03(181.11-264.02)$ \\
Y402H heterozygous (\%) & 37.3 & 58.5 \\
Y402H heterozygous (fH; mg/L) & $266.97 \pm 27.73(201.46-309.53)$ & $336.52 \pm 80.62(120.49-498.76)$ \\
Y402H heterozygous (H402; mg/L)* & $138.47 \pm 27.14(87.06-209.57)$ & $161.53 \pm 39.11(54.37-260.90)$ \\
Y402H heterozygous (Y402; mg/L)* & $128.50 \pm 26.27(50.84-160.15)$ & $175.00 \pm 51.34(59.12-270.79)$ \\
Y402/H402 allele frequency & $0.73 / 0.27$ & $0.59 / 0.41$
\end{tabular}

$\mathrm{fH}-\mathrm{Y} 402 \mathrm{H}$ polymorphic status was assigned from the ELISA and confirmed by sequencing. The total fH concentration and concentrations (in $\mathrm{mg} / \mathrm{L}$ ) of each variant were determined in each subgroup.

*Values are mean \pm SD (range) 
fore needed to identify the polymorphic status of the patient and also to give information on the plasma levels of $\mathrm{fH}$ protein. To this end, we first generated a panel of mAbs against SCR6 - 8 of $\mathrm{fH}$ and screened these for mAbs that specifically detected only one of theY $402 \mathrm{H}$ polymorphic variants. One mAb, termed MBI-7, was strongly reactive against $\mathrm{fH}-\mathrm{H} 402$ and showed no reactivity against $\mathrm{fH}-\mathrm{Y} 402$ in multiple tests. This mAb specifically bound native fH-H402 in ELISA and immunoaffinity purification protocols and denatured $\mathrm{fH}-\mathrm{H} 402$ after SDS-PAGE and Western blotting.

These findings demonstrate that this single, nonconservative amino acid change is sufficient to create a unique epitope in fH-H402. Indeed, a recent paper describes the production of polyclonal antipeptide antibodies that, after multiple adsorption and purification steps, differentiate the $\mathrm{fH}-\mathrm{Y} 402 \mathrm{H}$ variants in Western blot analysis. ${ }^{36}$ However, no fluid-phase binding data were presented for these reagents, suggesting that, in common with many antipeptide reagents, they detect only the denatured molecule and are unsuitable for ELISA or other fluid-phase assays. There are numerous precedents in the literature in which single-residue substitutions have been shown to create or delete an epitope for a specific $\mathrm{mAb}$ in a large protein, such as mAbs that differentiate hemoglobins A and $S^{37}$ and placental and germ-line alkaline phosphatase. ${ }^{38}$ Often, these changes are associated with conformational changes in the protein that amplify the differences between the two forms. ${ }^{39,40}$ Several recent studies have investigated the structural consequences of the $\mathrm{fH}-\mathrm{Y} 402 \mathrm{H}$ polymorphism. Comparison by ultracentrifugation and x-ray scattering of fH SCR6-8 constructs containing either $\mathrm{H}$ or $\mathrm{Y}$ at the relevant position in SCR7 revealed no major differences other than a small increase in self-association for the former, ${ }^{41}$ while comparison of nuclear magnetic resonance structures of SCR7 containing $\mathrm{H}$ or $\mathrm{Y}$ at the relevant position showed that they were almost identical. ${ }^{42}$ These reports suggest that there are no major conformational changes associated with the polymorphism. Comparison of crystal structures, already solved for the SCR6-8 construct containing $\mathrm{H}$ at the relevant position in $\mathrm{SCR} 7,{ }^{43}$ will provide a definitive answer to the degree of conformational change.

The mAb MBI-7 was used to develop a simple and robust assay for measurement of $\mathrm{fH}$ and the variants in plasma. The assay correctly identified the polymorphic status of all participants tested, confirmed by sequencing. ELISA and other antibody-based methods are the bedrock of the clinical immunology laboratory, and all necessary equipment and expertise are in place; in contrast, molecular detection of mutations requires access to patient DNA, specialist equipment, and expertise that is less widely available and more commonly found in the clinical genetics laboratory. The simplicity of the ELISA described here means that it could, subject to appropriate ethical constraints, be adopted by any clinical immunology laboratory, either in its current form or as a dip-stick test, to identify from a plasma sample the polymorphic status of those at risk for AMD. The association of noncoding and synonymous exonic polymorphisms in $\mathrm{fH}$ with AMD strongly suggests that altered expression, ${ }^{32}$ hence measurement of plasma concentration of $\mathrm{fH}$, will likely provide important additional information. Current clinical assays for quantification of $\mathrm{fH}$ use radial immunodiffusion or related methods and are compromised by the lack of international standards for $\mathrm{fH}$ measurement. The ELISA described here not only provides a measure of total $\mathrm{fH}$ but also a measure in those who are heterozygous of the amount of each form of $\mathrm{fH}$ in the plasma, a neglected parameter that may have major significance for understanding the roles of $\mathrm{fH}$ in health and disease. Analysis of plasma from healthy young volunteers showed that total fH levels varied widely, a finding previously attributed to genetic variation. ${ }^{35}$ The $\mathrm{fH}-\mathrm{Y} 402 \mathrm{H}$ polymorphic status was easily assigned in this population and showed $100 \%$ agreement with genotyping. Plasma levels of $\mathrm{fH}$ were similar regardless of polymorphic status.

Plasma from a Spanish cohort of AMD patients and age- and sex-matched controls was then tested in the assay. Samples were assayed blind, and assignation of phenotype was made before knowledge of the genetic analyses; all patients and controls were correctly assigned in the ELISA. The elderly control group had significantly higher plasma levels of $\mathrm{fH}$ than the younger control group, in agreement with previous data. ${ }^{35}$ Of note, these two control groups were not matched for other relevant factors such as smoking behavior, so no attempt was made here to directly compare the groups. Total $\mathrm{fH}$ levels of AMD patients were slightly higher than levels of the matched elderly controls. fH levels in the H402 homozygous, Y402 homozygous, and heterozygous subgroups were similar in elderly controls, but in AMD patients, fH levels were significantly higher in the heterozygous subgroup than in the other subgroups, and both variants were increased to a similar extent. We have no explanation for these differences and await confirmation in other cohorts.

The specificity of mAb MBI-7 for $\mathrm{fH}-\mathrm{H} 402$ was retained, even after denaturation in Western blots. Our preliminary data show that this mAb also detects $\mathrm{fH}$ in immunohistochemical staining in tissues; we are confirming its specificity in this context before applying it to AMD tissue to further explore the roles of $\mathrm{fH}$ in pathology. The capacity to differentiate between the $\mathrm{fH}$ isoforms deposited in tissue may prove helpful in further elucidating mechanisms in AMD and other diseases in which $\mathrm{fH}$ is known to be deposited in the tissues.

The mechanism by which the fH-H402 variant increases risk for AMD has been the subject of intense interest in the past 2 years. It has been suggested that $\mathrm{fH}-\mathrm{H} 402$ shows reduced binding to C-reactive protein, heparin, and cell surfaces, perhaps resulting in reduced capacity to protect cells, and that this deficit extends to fHL-1-H402. ${ }^{36,44-46}$ However, others have found no difference in binding of the variants to relevant targets. ${ }^{47}$ Further work is needed to elucidate the mechanism, and the reagents described here may facilitate these studies. Understanding of the mechanism and the precise roles of $\mathrm{fH}$ and complement activation will guide therapies targeted at $\mathrm{fH}$ itself or to inhibit complement activation locally or systemically.

\section{References}

1. Weiler JM, Daha MR, Austen KF, Fearon DT. Control of the amplification convertase of complement by the plasma protein $\beta \mathrm{lH}$. Proc Natl Acad Sci US A. 1976;73:3268-3272.

2. Rodriguez de Cordoba S, Esparza-Gordillo J, Goicoechea de Jorge E, Lopez-Trascasa M, Sanchez-Corral P. The human complement factor $\mathrm{H}$ : functional roles, genetic variations and disease associations. Mol Immunol. 2004;41:355-367.

3. Botto M, Walport MJ. Hereditary deficiency of $\mathrm{C} 3$ in animals and humans. Int Rev Immunol. 1993;10:37-50.

4. Reis E, Falcao DA, Isaac L. Clinical aspects and molecular basis of primary deficiencies of complement component C3 and its regulatory proteins factor I and factor H. Scand J Immunol. 2006;63: 155-168.

5. Rodriguez de Cordoba S, Goicoechea de Jorge E. Translational mini-review series on complement factor $\mathrm{H}$ : genetics and disease associations of human complement factor H. Clin Exp Immunol. 2008; 151:1-13

6. Bird AC, Bressler NM, Bressler SB, et al. An international classification and grading system for age-related maculopathy and agerelated macular degeneration: the International ARM Epidemiological Study Group. Surv Opbthalmol. 1995;39:367-374.

7. Edwards AO, Ritter R 3rd, Abel KJ, Manning A, Panhuysen C, Farrer LA. Complement factor $\mathrm{H}$ polymorphism and age-related macular degeneration. Science. 2005;308:421-424. 
8. Hageman GS, Anderson DH, Johnson LV, et al. A common haplotype in the complement regulatory gene factor $\mathrm{H}$ (HF1/CFH) predisposes individuals to age-related macular degeneration. Proc Natl Acad Sci U S A. 2005;102:7227-7232.

9. Haines JL, Hauser MA, Schmidt S, et al. Complement factor $\mathrm{H}$ variant increases the risk of age-related macular degeneration. Science. 2005;308:419-421.

10. Klein RJ, Zeiss C, Chew EY, et al. Complement factor $\mathrm{H}$ polymorphism in age-related macular degeneration. Science. 2005;308: 385-389.

11. Jakobsdottir J, Conley YP, Weeks DE, Mah TS, Ferrell RE, Gorin MB. Susceptibility genes for age-related maculopathy on chromosome 10q26. Am J Hum Genet. 2005;77:389-407.

12. Rivera A, Fisher SA, Fritsche LG, et al. Hypothetical LOC387715 is a second major susceptibility gene for age-related macular degeneration, contributing independently of complement factor $\mathrm{H}$ to disease risk. Hum Mol Genet. 2005;14:3227-3236.

13. Kaur I, Hussain A, Hussain N, et al. Analysis of CFH, TLR4, and APOE polymorphism in India suggests the Tyr402His variant of $\mathrm{CFH}$ to be a global marker for age-related macular degeneration. Invest Ophthalmol Vis Sci. 2006;47:3729-3735.

14. Lau LI, Chen SJ, Cheng CY, et al. Association of the Y402H polymorphism in complement factor $\mathrm{H}$ gene and neovascular age-related macular degeneration in Chinese patients. Invest Ophthalmol Vis Sci. 2006;47:3242-3246.

15. Gotoh N, Yamada R, Hiratani H, et al. No association between complement factor $\mathrm{H}$ gene polymorphism and exudative agerelated macular degeneration in Japanese. Hum Genet. 2006;120: $139-143$.

16. Uka J, Tamura H, Kobayashi T, et al. No association of complement factor $\mathrm{H}$ gene polymorphism and age-related macular degeneration in the Japanese population. Retina. 2006;26:985-987.

17. Harris CL, Lublin DM, Morgan BP. Efficient generation of monoclonal antibodies for specific protein domains using recombinant immunoglobulin fusion proteins: pitfalls and solutions. J Immunol Methods. 2002a:268:245-258.

18. Harris CL, Williams AS, Linton SM, Morgan BP. Coupling complement regulators to immunoglobulin domains generates effective anti-complement reagents with extended half-life in vivo. Clin Exp Immunol. 2002b;129:198-207.

19. Harris CL, Hughes CE, Goodfellow I, Evans DJ, Caterson B, Morgan BP. Generation of anti-complement 'prodrugs': cleavable reagents for specific delivery to disease sites. J Biol Chem. 2003;278: 36068-36076.

20. Kohler G, Milstein C. Continuous cultures of fused cells secreting antibody of predefined specificity. Nature. 1975;256:495-499.

21. Sim E, Palmer MS, Puklavec M, Sim RB. Monoclonal antibodies against the complement control protein factor $\mathrm{H}$ (beta $1 \mathrm{H}$ ). Biosci Rep. 1983;3:1119-1131.

22. Hayashi Y, Matsuda R, Maitani T, et al. An expression of withinplate uncertainty in sandwich ELISA.J Pharm Biomed Anal. 2004; 36:225-229.

23. DiScipio RG. Factor H. In: Morley BJ, Walport MJ, eds. The Complement Facts Book. London: Academic Press; 2000:168-173.

24. Johnson LV, Ozaki S, Staples MK, Erickson PA, Anderson DH. A potential role for immune complex pathogenesis in drusen formation. Exp Eye Res. 2000;70:441-449.

25. Johnson LV, Leitner WP, Rivest AJ, Staples MK, Radeke MJ, Anderson DH. The Alzheimer's A beta -peptide is deposited at sites of complement activation in pathologic deposits associated with aging and age-related macular degeneration. Proc Natl Acad Sci U S A. 2002;99:11830-11835.

26. Nozaki M, Raisler BJ, Sakurai E, et al. Drusen complement components $\mathrm{C} 3 \mathrm{a}$ and $\mathrm{C} 5 \mathrm{a}$ promote choroidal neovascularization. Proc Natl Acad Sci U S A. 2006;103:2328-2333.

27. Hageman GS, Hancox LS, Taiber AJ, et al. Extended haplotypes in the complement factor $\mathrm{H}(\mathrm{CFH})$ and $\mathrm{CFH}-$ related (CFHR) family of genes protect against age-related macular degeneration: characterization, ethnic distribution and evolutionary implications. Ann Med. 2006;38:592-604.
28. Hughes AE, Orr N, Esfandiary H, Diaz-Torres M, Goodship T, Chakravarthy U. A common CFH haplotype, with deletion of CFHR1 and CFHR3, is associated with lower risk of age-related macular degeneration. Nat Genet. 2006;38:1173-1177.

29. Yates JR, Sepp T, Matharu BK, et al. Genetic factors in AMD study group: complement $\mathrm{C} 3$ variant and the risk of age-related macular degeneration. N Engl J Med. 2007;357:553-561.

30. Gold B, Merriam JE, Zernant J, et al. Variation in factor B (BF) and complement component 2 (C2) genes is associated with agerelated macular degeneration. Nat Genet. 2006;38:458-462.

31. Spencer KL, Hauser MA, Olson LM, et al. Protective effect of complement factor B and complement component 2 variants in age-related macular degeneration. Hum Mol Genet. 2007;16: $1986-1992$

32. Francis PJ, Schultz DW, Hamon S, Ott J, Weleber RG, Klein ML. Haplotypes in the complement factor $\mathrm{H}(\mathrm{CFH})$ gene: associations with drusen and advanced age-related macular degeneration. PLoS ONE. 2007;2:e1197.

33. Seddon JM, George S, Rosner B, Klein ML. CFH gene variant, $\mathrm{Y} 402 \mathrm{H}$, and smoking, body mass index, environmental associations with advanced age-related macular degeneration. Hum Hered. 2006;61:157-165.

34. Seddon JM, Francis PJ, George S, Schultz DW, Rosner B, Klein ML. Association of CFH Y402H and LOC387715 A69S with progression of age-related macular degeneration. JAMA. 2007;297:1793-1800.

35. Esparza-Gordillo J, Soria JM, Buil A, et al. Genetic and environmental factors influencing the human factor $\mathrm{H}$ plasma levels. Immunogenetics. 2004;56:77-82.

36. Yu J, Wiita P, Kawaguchi R, et al. Biochemical analysis of a common human polymorphism associated with age-related macular degeneration. Biochemistry. 2007;46:8451-8461.

37. Stanker LH, Branscomb E, Vanderlaan M, Jensen RH. Monoclonal antibodies recognizing single amino acid substitutions in hemoglobin. J Immunol. 1986;136:4174-4180.

38. Hoylaerts MF, Millán JL. Site-directed mutagenesis and epitopemapped monoclonal antibodies define a catalytically important conformational difference between human placental and germ cell alkaline phosphatase. Eur J Biochem. 1991;202:605-616.

39. De Vito LD, Mason BP, Jankowska-Gan E, et al. Epitope fine specificity of human anti-HLA-A2 antibodies: identification of four epitopes including a haptenlike epitope on HLA-A2 at lysine 127. Hum Immunol. 1993;37:165-177.

40. Mani JC, Marchi V, Cucurou C. Effect of HIV-1 peptide presentation on the affinity constants of two monoclonal antibodies determined by Biacore technology. Mol Immunol. 1994;31:439-444.

41. Fernando AN, Furtado PB, Clark SJ, et al. Associative and structural properties of the region of complement factor $\mathrm{H}$ encompassing the Tyr402His disease-related polymorphism and its interactions with heparin. J Mol Biol. 2007;368:564-581.

42. Herbert AP, Uhrín D, Lyon M, Pangburn MK, Barlow PN. Diseaseassociated sequence variations congregate in a polyanion recognition patch on human factor $\mathrm{H}$ revealed in three-dimensional structure. J Biol Chem. 2006;281:16512-16520.

43. Prosser BE, Johnson S, Roversi P, et al. Expression, purification, cocrystallization and preliminary crystallographic analysis of sucrose octasulfate/human complement regulator factor H SCRs 6-8. Acta Crystallograph Sect F Struct Biol Cryst Commun. 2007; 63:480 - 483 .

44. Laine M, Jarva H, Seitsonen S, et al. Y402H polymorphism of complement factor $\mathrm{H}$ affects binding affinity to C-reactive protein. J Immunol. 2007;178:3831-3836.

45. Skerka C, Lauer N, Weinberger AA, et al. Defective complement control of factor $\mathrm{H}(\mathrm{Y} 402 \mathrm{H})$ and FHL-1 in age-related macular degeneration. Mol Immunol. 2007;44:3398-3406.

46. Sjoberg AP, Trouw LA, Clark SJ, et al. The factor $\mathrm{H}$ variant associated with age-related macular degeneration (His-384) and the nondisease-associated form bind differentially to C-reactive protein, fibromodulin, DNA, and necrotic cells. J Biol Chem. 2007;282: $10894-10900$.

47. Biro A, Rovo Z, Papp D, et al. Studies on the interactions between C-reactive protein and complement proteins. Immunology. 2007; $121: 40-50$ 